\title{
The Integration of Development of Information Industry and Pension Service Industry Using Grey Relational Analysis (GRA): The Case Study of Handan City, China
}

\author{
Xin $\mathrm{An}^{1, *}$, Yong-Seung $\mathrm{Ji}^{2}$, Wei-ping Gu${ }^{3}$ and Dong-Joo Kim ${ }^{4}$ \\ 1Department of Economics and Management, Handan University, Handan, China; happyanxin@163.com \\ 2Department Division of Liberal Arts, Woosuk University, Wanju, South Korea; enerji70@gmail.com \\ ${ }^{3}$ Nanjing Institute of Industry Technology, Nanjing, China; veasnag@163.com \\ 4Department of Rehabilitation Studies, Woosuk University, Wanju, South Korea; ju7055@naver.com
}

\begin{abstract}
Background/objectives: The integration of information industry and pension industry has become a new growth point for the regional economy. To achieve its deep integration, it is necessary to analyse the fusion mechanism and make scientific measures of the level of integration. This study aims to analyse the circumstances of the integration of information industry and pension industry from the practice level of industrial integration. Method/statistical analysis: Due to the wide range of the pension industry and the lack of large-scale representative enterprises, the overall industrial information collection is difficult. Therefore, the grey relational analysis method is selected to establish the fusion level measurement model. According to the 2011-2017 Statistical Yearbook of Handan city in China, eight related industries were selected as reference series, and Excel 2016 program calculation was used to complete the empirical research. Findings: According to the results, the average level of integration of eight related industries of Handan city in China is 0.74913 , of which the information industry and the e-pension industry are 0.64909 , ranking seventh, information industry and leasing and business services. The degree of integration is up to 0.84005 . The low level of integration between the information industry and the pension industry is highly likely to impede regional economic growth. Improvement/application: In this study, the grey relational analysis showed that the level of integration between the information industry and the pension industry in China was identified, and that it was still in the early stages of integration. It also presented policy alternatives to speed up the development of industry integration in terms of consumer, market and technological improvement, and system innovation.
\end{abstract}

Keywords: Information Industry, Pension Industry, Industrial Integration, Grey Relational Analysis.

\section{Introduction}

At present, China's economic development has matured and entered a new normal situation. Inter-industry integration has become a new impetus for industrial development and economic growth. Since the integration between industries, many emerging industries have been developed. The rapid development of the information industry has changed the traditional trading venues, expanded trading hours, enriched trading categories, accelerated transaction speed, and reduced intermediate links. 1 The Internet has had a wide and profound impact on all aspects of society, and has entered an era of great change, the major development and great integration. $\underline{2}$

${ }^{*}$ Author for correspondence 
Due to the late start of the development of China's pension industry, the characteristics of the industry with large investment and low income are common. Therefore, it is inevitable that the pioneers feel great resistance in terms of technology, capital, and talents. . $^{3}$ The so-called concept of openness, equality, innovation, and sharing advocated by the Internet information industry can provide new opportunities for the upgrading and transformation of traditional industries through the integration with the pension industry.

In most parts of China, new industries integrating between Internet information industry and pension service industry have been developed in practice. In the process of integrating the two industries, the degree of integration in different regions may be different depending on the environment. It is clear that the level of integration in a region is of substantial importance in addressing regional economic and social development, and solving the problem of population aging. $\underline{4}$

Industrial integration, as a new industrial evolution phenomenon that accompanied the information technology innovation in the 1970s and 1980s, has an important impact on promoting industrial restructuring and promoting economic transformation and upgrading.

In Ref., 5 American industrial economist wrote in the Harvard Business Review: In the process of industrial integration, new competitive synergies are often formed between participating entities, resulting in more complex economic benefits. In Ref., $\underline{6}$ Weiwei also proposed: Industry integration is the dynamic evolution of the mutual penetration and extension of different industries or the reorganisation of various industries within the same industry. The result is a new industry or new point of economic growth. In fact, many foreign studies have shown that the industrial integration theory takes the information industry as the starting point and extends to the primary industry, the secondary industry and the tertiary industry, and gradually forms some new industries with characteristics.

Chinese scholars have studied the integration of information industry and pension industry, and the research content is roughly divided into the following three categories: The first is the necessity of the integration of information industry and pension service. The in-depth integration of Internet information technology and pension service industry can improve the efficiency of resource use, change the traditional information exchange and transmission mode,,$\underline{7}$ and solve the existing problems of community pension service. $\stackrel{8}{ }$ Mitigating the risks to the ability of families to provide for old age as a result of China's declining birth rate. To the greatest extent to meet the needs of the elderly, enhance the independence and autonomy of the elderly, improve the quality and efficiency of elderly health care. ${ }^{9}$

The second category is the integration of information industry and old-age service. The second type is the fusion type of information industry and old-age service. To establish an Internet of Things (IoTs) application platform for long-term care services for disabled or semidisabled elderly people, and provide information and standardised home care model. $\underline{10}$ To build a supply and demand platform for old-age care services is based on Internet technology. 11 To establish a social support system for old-age care services for disabled elderly people can be socialised and market-oriented. $\underline{12, \underline{13}}$

The third category is the gridlock problem of the integration of information industry and pension industry. The development of intelligent elderly care is a revolution in the traditional pension field, $\underline{14}$ but the application of information technology in the elderly care service industry still has problems such as uneven distribution of elderly care resources, narrow income coverage of high-quality intelligent elderly care projects, and lack of informatisation standards for elderly care services..$\underline{15}$ The overall project has the disadvantages of large investment scale and long payback period, and there is the risk of dissimilation of investment in the implementation process. $\underline{16}, \underline{17}$

Through the literature review, the following research questions were raised. First of all, qualitative analysis was adopted in most research methods, while quantitative analysis was rare. Secondly, the research focuses on the necessity, mode and dilemma of the integration of informatisation and elderly care services, while the realisation mechanism of industrial integration is few. Only by analyzing fusion mechanisms and scientifically measuring the level of fusion can fusion and improvement be more precisely at target levels in order to solve the social problems caused by the aging population.

Traditional analysis methods of fusion level are mainly represented index measurement algorithm, patent data method, AHP-fuzzy comprehensive evaluation method, and grey relational analysis method. Herfindahl index measurement algorisms require large representative companies, and the pension industry does not have this function, and this method has certain flaws. The patent 
law should build a correlation coefficient matrix of the degree of integration among industries according to the number of industry patents, while Chinese patent statistics are not classified by industry and data collection is very difficult. The key to the AHP-fuzzy comprehensive evaluation method is to propose an accurate and objective indicator system for measuring the degree of industry integration. However, this method is not advantageous because it is currently difficult to obtain detailed data on the production value of the aging industry.

The grey relational analysis is a method of distinguishing the degree of correlation between factors according to the degree of similarity or difference between various factors of the system. There are no strict requirements for sample size, and mathematical methods are used to process projects that are difficult to use or only have a small amount of observational data. The development of known information provides an accurate description and understanding of the real world.

China's pension industry encompasses a wide range of industries, and because there are no large corporations, it is difficult to gather complete industrial information. In addition, the relationship between the information and the pension industry has complexity of industry boundaries, instability of dynamic change, incompleteness, and uncertainty in index data. Thus, the grey system theory can be used to evaluate the size of the pension industry, which can expand information sources and improve the reliability of assessment and analysis under incomplete and inaccurate information conditions. It has the advantages of simple operation, high efficiency, low data requirements, and clear disclosure. This method of analysis is not only the basis of the analysis of advantages, but also the basis of scientific decision-making. Of course, due to the complexity of the socioeconomic system, the grey system theory always faces various problems in its practical application. For example, how to correctly select one of the quantitative models of grey correlation degree to perform correlation analysis on a particular sequence, how to correctly select the resolution coefficient of grey correlation degree to make the result more accurate, and negative correlation and zero correlation analysis models are all topics to discuss in the future.

Therefore, this research intends to measure the level of integration between the information industry and the pension service industry in Handan city. In addition, this research proposes policy alternatives on how to measure and utilise the level of integration and how to solve the social problems of the old population in China.

\section{Industry Boundary}

\subsection{Information Industry Boundary}

The information technology industry, also known as the information industry, is an industry that uses information means and technology to collect, organise, store, and transmit information, provide information services such as information and related services. $\underline{18}$ The information technology industry includes an industry sector engaged in the production, distribution and sale of information, and the use of information providing services. $\frac{19}{}$

In this production process, various Internet resources are transformed into various types of information services and product technologies, forming the technological boundaries of the information industry. The information content embodied in various forms constitutes the product boundary of the information industry through the information products. Production processes and information dissemination channels form the business and operational boundaries of the information industry, while the exchange services provided by information services and products constitute the scope of the industry boundary of the information industry $\underline{\underline{20}}$ (Figure 1).

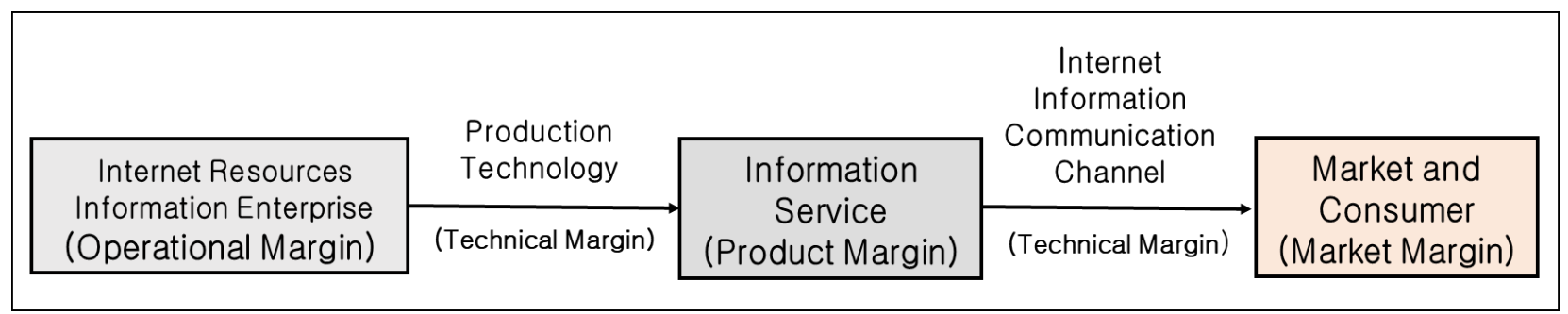

Figure 1. Information industry boundary. 


\subsection{Pension Industry Boundary}

Carroll first proposed the concept of Silver Market. 1 The pension industry refers to the specific industries that are built around the content of the old-age care and are related to the relevant industries that have different interests and different divisions of labor. .22 The pension industry has the natural attributions of economic activity. The process is to transform various pension resources into specific pension service products. After the service products enter the pension industry, they operate according to the operating mode of the market economy and obtain certain economic benefits.

Pension resources are the basis for the development of the pension industry, including economic resources and environmental resources, as well as the need for resources for the elderly and external resources. $\underline{23}$ In order to pass these old-age resources to the elderly, it is necessary to process the old-age resources by technical means, and develop corresponding pension service products according to the specific technical standards, and finally transmit them through the specific sales and clearing channels of the pension market. From the perspective of the business process of the pension industry, the pension industry conducts various economic activities within a specific industrial boundary. $\underline{\underline{24}}$

In this complete process, the development technology of pension resources forms the technical boundary of the pension industry, and the various developed aged care products from the product boundary of the pension industry. The sales and channel of the old-age service products from the business and the operational boundary of the pension industry, while the pension market that provides sales and clearing channels forms the market boundary of the pension industry (Figure 2).

\subsection{Integration Boundary of Mechanism on Information and Pension Industry}

Industrial integration is a gradual process of penetration. .55 With the maturity and improvement of the information plus pensions market, the resource elements of the information and pension sectors will be become more open competition in the long term of industrial development. $\underline{26}$ New independent sector fully circulated and spread in the environment to attract other industry sectors to participate in market integration, to further expand the value growth space of the information plus pension industry market, and to promote economic growth point of information plus pension of emerging economic phenomena or information business system (Figure 3). .27 It will fully circulate and spread in the environment to induce other industry sectors to participate in market consolidation, to further expand the value growth space of the information plus pension industry market, and to promote emerging economic growth.

This may mean that in the integration of information industry and pension industry, the information and pension market will realise a $1+1>2$ state transition in future development.

\section{Research Materials and Methods}

\subsection{Research Target and Collecting Survey}

Handan City is in the heart of China. According to the national surveys and population change surveys, the population aged 15-64 fell from 66,270,000 in 2011 to $6.506,600$ in 2017 and the labor force decreased by $1,244,005$. The population over the age of 65 has increased

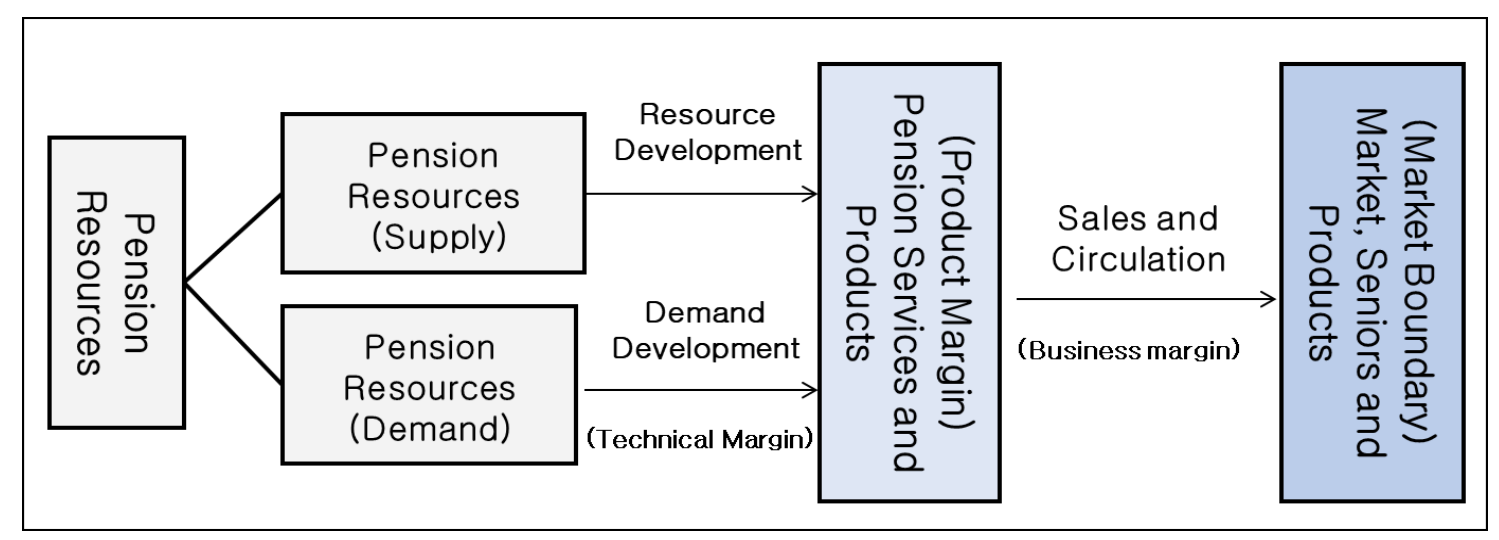

Figure 2. Pension industry boundary. 


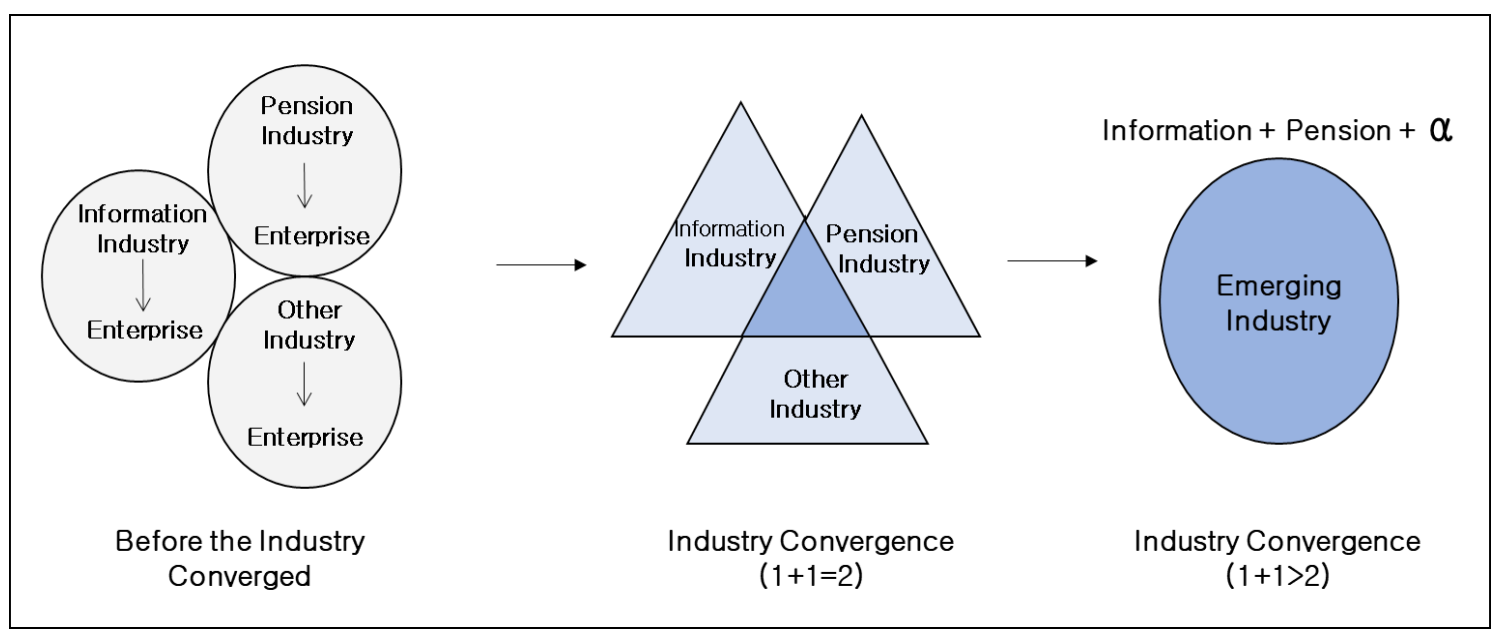

Figure 3. The integration process of the trend of "information + pension industry".

from 647,100 in 2011 to 954,200 in 2017 , while the elderly population has increased by 207,100 . The proportion of the elderly population 65 years and older increased from $6.94 \%$ in 2011 to $10.81 \%$ in 2017 . The size of the elderly population continues to grow, and its proportion is increasing. According to the China Handan City Statistical Yearbook (2011-2017), eight related industries were selected as reference series in this research.

\subsection{Research Methods}

In this research, the grey relational analysis can be studied in the current integration of the information industry and the pension industry: 1) the grey relational analysis method is derived from the grey system theory, and can analyse the dynamic history of all variables. By analysing known information, this method is typically used to measure the proximity of economic and social indicators of different industries in the annual curve space, which processes variables in a dimensionless manner. Therefore, this method can overcome the inconsistencies of the selected variable units, and the advantages of this method are obvious, especially in the present situation, where it is difficult to obtain detailed data on the output values of the information industry and the aging industry; 2) the grey correlation of industry indicates the proximity of industry indicators, the latter reflects the degree of industrial integration, because it can more objectively explain the degree of cross-industry impact. The higher the grey correlation, the higher does the degree of integration. It can be seen that the grey relational analysis between the information and the pension industry integration measurement is scientific and feasible. And Excel 2016 program calculations were used to the empirical research.

\subsection{Grey Relational Analysis Procedure}

\subsubsection{Determination of the Reference Sequence}

For the convenience of explanation, this research specifically describes how to determine the order of reference using a sample of relevant industry from 2011 to 2017. In other words, identifying the parent sequence or dependent variable data as a comparison is the factor affected by the problem. In general, the value of the first moment is $x_{0}(1)$, the value of the second moment $x_{0}(2)$, $\ldots$, and the value of the $k$-th moment is $x_{0}(k)$.

$$
x_{0}(k)=\left\{x_{0}(1), x_{0}(2), \ldots, x_{0}(n)\right\}(k=1 \ldots n)
$$

\subsubsection{Determination of the Comparison Sequence}

To compare sequences, this research uses the determination of $x_{1}$ as an example for illustration. First of all, this research calculates the data for 2011 and then uses the formula to obtain a score for the average and the first element of the relevant industry, evaluated by the date for 2011. And it is expressed as follows:

$$
\begin{aligned}
& x_{1}(k)=\left\{x_{1}(1), x_{1}(2), \ldots, x_{1}(n)\right\}(k=1 \ldots n) \\
& x_{2}(k)=\left\{x_{2}(1), x_{2}(2), \ldots, x_{2}(n)\right\}(k=1 \ldots n)
\end{aligned}
$$




\subsubsection{Using the Equalisation Method to Eliminate Dimensions from the Variable Sequences}

To resolve incompatibilities between sequences due to different units of measurement, parent sequences and subsequences should not have dimensions. Common dimensionless processing methods include centralisation, initialisation, and averaging. This research adopts an initial evaluation method. The specific calculation method is as follows:

$$
x_{0}^{\prime}(k)=\left\{\frac{x_{0}(1)}{x_{0}(1)}, \frac{x_{0}(2)}{x_{0}(1)}, \ldots, \frac{x_{0}(n)}{x_{0}(1)}\right\}(k=1 \ldots n)
$$

In this way, this research yields dimensionless reference sequences and comparison sequences.

\subsubsection{Solving the Grey Relational Coefficient}

Taking the first element of the relevant industry during the remedy of the grey relational coefficient as an example, the research brings the dimensionless variable sequences $x_{0}$ and $x_{1}$ into the formula for calculating the grey relational coefficient:

$\xi_{0 i}(k)=\frac{\lim _{i} \lim _{k}\left|x_{0}^{\prime}(k)-x_{i}^{\prime}(k)\right|+\rho \max _{i} \max _{k}\left|x_{0}^{\prime}(k)-x_{i}^{\prime}(k)\right|}{\left|x_{0}^{\prime}(k)-x_{i}^{\prime}(k)\right|+\rho \max _{i} \max _{k}\left|x_{0}^{\prime}(k)-x_{i}^{\prime}(k)\right|}$

\subsubsection{Solving the Grey Relevancy}

In order to prevent the information reflected by the correlation coefficient from being excessively distributed, the correlation between each subsequence and the parent sequence can be compared as a whole. The coefficient of the grey relational analysis between the eight factors and the 2011-2017 data is calculated by the formula $r_{0 i}=\frac{1}{n} \sum_{i}^{n} \xi_{0 i}(k)$ below to obtain the grey relevancy of each element.

\section{Results}

\subsection{Characteristics of the Subjects}

The factors of this research include information industry boundaries (operational boundaries, technology boundaries, product boundaries, and market boundaries) and pension industry boundaries (technology boundaries, product boundaries, and market boundaries). This boundary is the convergence point of the industry's future. Policy recommendations are based on these convergence points (consumer demand, technology, and market).

All eight of these industries are related to the pension industry and can be developed together with the pension industry. In the fusion mechanism, information + pension $+\mathrm{X}$ is also mentioned. After categorisation, we can choose a highly integrated industry to integrate the pension industry and produce corresponding new products or services to enhance the informatisation of the pension industry.

Therefore, this research studies the following factors. From 2011 to 2017, the value-added $\left(X_{0}\right)$ of the information transmission, software and information technology services industry and the number of elderly people over 65 years old $\left(X_{1}\right)$ in Handan City, the original data are selected to introduce the relationship with information transmission, software and information technology services. Closed wholesale and retail value added $\left(X_{2}\right)$; accommodation and food value added $\left(X_{3}\right)$; financial industry value added $\left(X_{4}\right)$; real estate value added $\left(X_{5}\right)$; leasing and business services value added $\left(X_{6}\right)$; culture, value added of sports and entertainment industry $\left(X_{7}\right)$ value added of agriculture, forestry, animal husbandry and sideline fishery $\left(X_{8}\right)$ as control data (Table 1).

\subsection{Dimensionless Processing of Assessment Data}

Since the meaning of the comparison between different dimensions is not clear, because different indicators have different units, the data are first processed without dimensions. In the grey system, each element has a different meaning and standard, which is similar to the enhancement factor. If it does not have the size of the original data, we should use the initial value method. This method removes the effects of dimensions and sizes while maintain differences in variable values (Tables 2 and 3 ).

\subsection{Difference Sequence and the Maximum and Minimum Values \\ Calculating the absolute value of each sequence difference means subtracting non-dimensional dependent variable data $x_{0}^{\prime}(k)$ from the independent variable data $x_{i}^{\prime}(k)$}


Table 1. Data of information, pension and related industries, Handan (2011-2017)

\begin{tabular}{|l|l|l|l|l|l|l|l|}
\hline & $\mathbf{2 0 1 1}$ & $\mathbf{2 0 1 2}$ & $\mathbf{2 0 1 3}$ & $\mathbf{2 0 1 4}$ & $\mathbf{2 0 1 5}$ & $\mathbf{2 0 1 6}$ & $\mathbf{2 0 1 7}$ \\
\hline$X_{0}$ & 317895 & 366421 & 438677 & 527403 & 620544 & 640544 & 718544 \\
\hline$X_{1}$ & 64.71 & 66.93 & 71.81 & 76.79 & 82.96 & 88.59 & 95.42 \\
\hline$X_{2}$ & 1123433 & 1352558 & 1611280 & 2037577 & 2404659 & 2930655 & 2603696 \\
\hline$X_{3}$ & 368609 & 419374 & 468957 & 517140 & 464924 & 506805 & 554188 \\
\hline$X_{4}$ & 519359 & 756234 & 867119 & 904014 & 1008882 & 1202744 & 1302765 \\
\hline$X_{5}$ & 628733 & 744925 & 802987 & 844695 & 916179 & 948631 & 1012404 \\
\hline$X_{6}$ & 164586 & 195084 & 234825 & 257583 & 333602 & 383518 & 452099 \\
\hline$X_{7}$ & 79441 & 111359 & 130315 & 148257 & 105811 & 121643 & 143250 \\
\hline$X_{8}$ & 2029177 & 2139638 & 2243549 & 2384964 & 2431562 & 2565180 & 2635342 \\
\hline
\end{tabular}

Source: The website of the Statistical Office of the People's Republic of China and the Statistical Yearbook of Handan City $\left(X_{1}\right.$ Unit:10,000 people; $X_{0}, X_{2}, X_{3}, X_{4}, X_{5}, X_{6}$, $X_{7}, X_{8}$ Unit: 10,000 RMB).

Table 2. The non-dimensionality of indexes for data from 2011 to 2017

\begin{tabular}{|l|l|l|l|l|l|l|l|}
\hline & $\mathbf{2 0 1 1}$ & $\mathbf{2 0 1 2}$ & $\mathbf{2 0 1 3}$ & $\mathbf{2 0 1 4}$ & $\mathbf{2 0 1 5}$ & $\mathbf{2 0 1 6}$ & $\mathbf{2 0 1 7}$ \\
\hline$x_{0}^{\prime}(k)$ & 1 & 1.15265 & 1.37994 & 1.65905 & 1.95204 & 2.01495 & 2.26032 \\
\hline$x_{1}^{\prime}(k)$ & 1 & 1.03431 & 1.10972 & 1.18668 & 1.28203 & 1.36903 & 1.47458 \\
\hline$x_{2}^{\prime}(k)$ & 1 & 1.20395 & 1.43425 & 1.81371 & 2.14046 & 2.60866 & 2.31762 \\
\hline$x_{3}^{\prime}(k)$ & 1 & 1.13772 & 1.27223 & 1.40295 & 1.26129 & 1.37491 & 1.50346 \\
\hline$x_{4}^{\prime}(k)$ & 1 & 1.45609 & 1.66959 & 1.74063 & 1.94255 & 2.31582 & 2.50841 \\
\hline$x_{5}^{\prime}(k)$ & 1 & 1.18480 & 1.27715 & 1.34349 & 1.45718 & 1.50880 & 1.61023 \\
\hline$x_{6}^{\prime}(k)$ & 1 & 1.18530 & 1.42676 & 1.56504 & 2.02692 & 2.33020 & 2.74689 \\
\hline$x_{7}^{\prime}(k)$ & 1 & 1.40178 & 1.64040 & 1.86625 & 1.33194 & 1.53124 & 1.80323 \\
\hline$x_{8}^{\prime}(k)$ & 1 & 1.05444 & 1.10564 & 1.17534 & 1.19830 & 1.26415 & 1.29872 \\
\hline
\end{tabular}

Table 3. The absolute value of difference sequence

\begin{tabular}{|l|l|l|l|l|l|l|l|}
\hline & $\mathbf{2 0 1 1}$ & $\mathbf{2 0 1 2}$ & $\mathbf{2 0 1 3}$ & $\mathbf{2 0 1 4}$ & $\mathbf{2 0 1 5}$ & $\mathbf{2 0 1 6}$ & $\mathbf{2 0 1 7}$ \\
\hline$\left|\Delta_{01}\right|$ & 0 & 0.11834 & 0.27022 & 0.47237 & 0.67001 & 0.64592 & 0.78574 \\
\hline$\left|\Delta_{02}\right|$ & 0 & 0.05130 & 0.05430 & 0.15466 & 0.18842 & 0.59371 & 0.05731 \\
\hline$\left|\Delta_{03}\right|$ & 0 & 0.01493 & 0.10771 & 0.25610 & 0.69075 & 0.64004 & 0.75686 \\
\hline$\left|\Delta_{04}\right|$ & 0 & 0.30344 & 0.28965 & 0.08159 & 0.00949 & 0.30087 & 0.24809 \\
\hline$\left|\Delta_{05}\right|$ & 0 & 0.03216 & 0.10279 & 0.31556 & 0.49486 & 0.50616 & 0.65009 \\
\hline$\left|\Delta_{06}\right|$ & 0 & 0.03265 & 0.04682 & 0.09401 & 0.07488 & 0.31524 & 0.48657 \\
\hline$\left|\Delta_{07}\right|$ & 0 & 0.24913 & 0.26046 & 0.20721 & 0.62010 & 0.48372 & 0.45709 \\
\hline$\left|\Delta_{08}\right|$ & 0 & 0.09821 & 0.27430 & 0.48371 & 0.75374 & 0.75081 & 0.96159 \\
\hline
\end{tabular}

, and finding the minimum and the maximum values to get the absolute value. The minimum value is 0 and the maximum value is 0.96159 . Then choose the maximum and the minimum values from the difference in the comparison sequences for each group: $\Delta_{0 \mathrm{i}}(\min )=0$; $\Delta_{0 \mathrm{i}}(\operatorname{man})=0.91529$. 


\subsection{Calculation of Correlation Coefficients}

The correlation coefficient reflects the proximity between the comparison sequence and the reference sequence. The larger the correlation coefficient, the higher does the degree of association between the comparison sequence and the reference sequence, and vice versa. The correlation coefficient can be calculated by the formula. $\rho$ is the resolution factor, and the purpose of the introduction is to reduce the influence of the limit on the calculation from 0 to 1 , usually 0.5 , and the value of $\rho$ is 0.5 .

\subsection{Comparing the Grey Relevancy}

The correlation coefficients represent the degree of association between data each time, and each time has a corresponding correlation coefficient, which does not help to compare the degree of association between industries, and does not allow sorting of cross-industry comparisons, so distributed information is needed. In central processing, the correlation is calculated according to the correlation coefficient. The formula for the relevance is as follows:

$$
r_{0 i}=\frac{1}{n} \sum_{i=1}^{n} \xi_{0 i}(k)
$$

The value is between 0 and 1 . The greater the degree of correlation, the higher the degree of the correlation between the comparison sequence and the reference sequence. The closer the curve shape is to the reference sequence, the more important the comparison sequence is to the reference sequence. According to the data in
Table 4, a correlation calculation formula is introduced as shown in Table 5.

\subsection{Ranking of Relevancy}

According to the results of correlation calculation (Figure 4 ), the grey correlation between the internet industry and industrial and related industries of the Handan city is $X_{8}$ $<X_{1}<X_{7}<X_{3}<X_{5}<X_{4}<X_{2}<X_{6}$, and related orders are pension industry and industry. And it reflects the close order of the information industry, with the industry with the highest gradation correlation closest and the highest degree of integration. Therefore, the degree of integration of the internet industry and various industries is in leasing and business services, wholesale and retail, finance, real estate, accommodation and catering, culture, sports and entertainment, pension industry, agriculture, forestry, animal husbandry, and fishery. The average degree of relevance is 0.74913 , the degree of integration between the information and the pension industry is 0.64909 , and the seventh place in the overall ranking is lower than the average. The highest is 0.84005 for the commercial service industry; the lowest is 0.63454 for agriculture, forestry, animal husbandry, and sideline fishery, and the pension industry ranks seventh.

This ranking can reflect the overall level of integration of the eight relevant industries and the information industry and the links between the eight industries, which can begin to develop new products or services and provide quantitative references to policy recommendations.

Table 4. Correlation coefficients of data

\begin{tabular}{|l|l|l|l|l|l|l|l|}
\hline & $\mathbf{2 0 1 1}$ & $\mathbf{2 0 1 2}$ & $\mathbf{2 0 1 3}$ & $\mathbf{2 0 1 4}$ & $\mathbf{2 0 1 5}$ & $\mathbf{2 0 1 6}$ & $\mathbf{2 0 1 7}$ \\
\hline$\xi_{01}(k)$ & 1 & 0.84257 & 0.70094 & 0.57279 & 0.48593 & 0.49509 & 0.44631 \\
\hline$\xi_{02}(k)$ & 1 & 0.92507 & 0.92103 & 0.80374 & 0.77072 & 0.51615 & 0.91703 \\
\hline$\xi_{03}(k)$ & 1 & 0.97697 & 0.85466 & 0.71207 & 0.47833 & 0.49737 & 0.45558 \\
\hline$\xi_{04}(k)$ & 1 & 0.67608 & 0.68619 & 0.88588 & 0.98524 & 0.67795 & 0.71854 \\
\hline$\xi_{05}(k)$ & 1 & 0.95168 & 0.86036 & 0.66745 & 0.56138 & 0.55581 & 0.49348 \\
\hline$\xi_{06}(k)$ & 1 & 0.95097 & 0.93117 & 0.87075 & 0.89428 & 0.66767 & 0.56553 \\
\hline$\xi_{07}(k)$ & 1 & 0.71769 & 0.70860 & 0.75349 & 0.50529 & 0.56698 & 0.58082 \\
\hline$\xi_{08}(k)$ & 1 & 0.86575 & 0.69779 & 0.56698 & 0.45660 & 0.45757 & 0.39710 \\
\hline
\end{tabular}

Table 5. Grey relevancy table of the eight factors

\begin{tabular}{|l|l|l|l|l|l|l|l|l|}
\hline Index & $r_{01}$ & $r_{02}$ & $r_{03}$ & $r_{04}$ & $r_{05}$ & $r_{06}$ & $r_{07}$ & $r_{08}$ \\
\hline & 0.64909 & 0.83625 & 0.71072 & 0.80427 & 0.72717 & 0.84005 & 0.69041 & 0.63454 \\
\hline
\end{tabular}




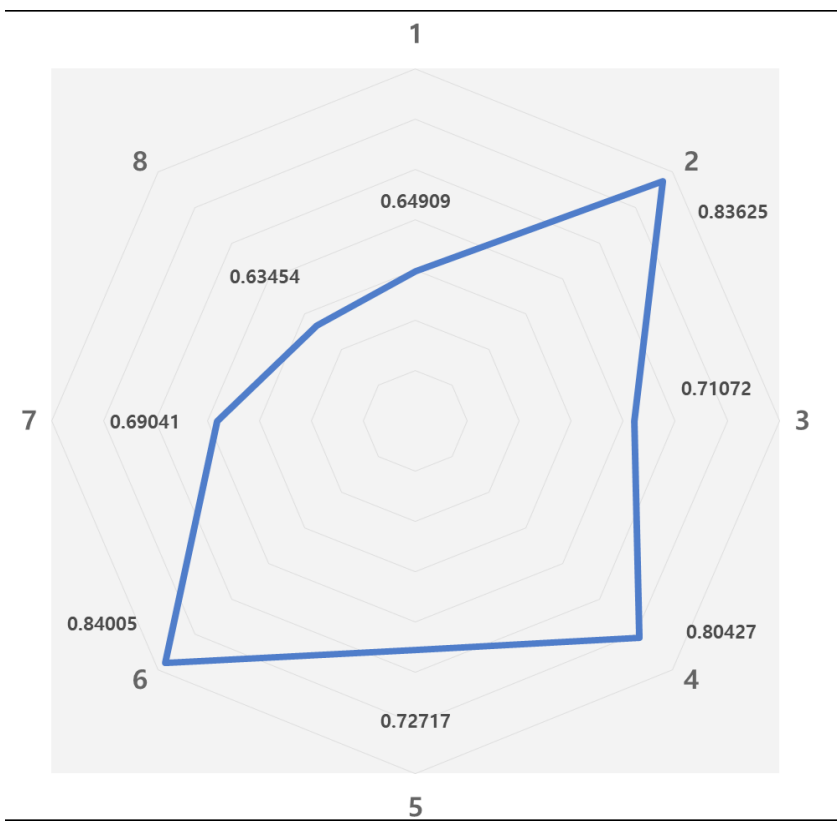

Figure 4. Radar maps of the key concepts obtained as correlation degree.

\section{Discussion}

The improvements of this research are as follows: first, the grey relational analysis applied evaluation model is proposed to evaluate the degree of integration between the information and the pension industry. In order to assess the degree of integration, the literature reviewed the boundary between the information and the pension industry and concluded the convergence mechanism of the information and the pension industry. Second, this model can be used to assess the degree of integration between industries and the government's assessment of related industries. Applying the grey relational analysis evaluates the degree of industrial integration, allowing us to more accurately assess the degree of integration between the information and the pension industry. In addition, clear results can be obtained by evaluation indicators by quantitative evaluation. This research also highlights the need to better understand industry integration as a multidisciplinary, multidimensional system that includes multiple components of consumption, supply, technology, and system environments.

The main conclusions of this research are as follows: first, the effective demand of elderly consumers is not enough. Information and pension products formed by integrated innovation face the problem of being able to adapt to the market when it comes to market. The key to the acceptance of integrated products is the consumption behaviors and habits of the elderly, depending on the path. In the current information pension market, there is an elderly consumer group with a group of learners who want to embrace and try to out new integrated products. Thus, while demand barriers are related to consumer maturity, the main problem is that suppliers are innovating and leading the market, as China's information pension market lacks a strong view of consumer spending or inertia.

Second, there is a lack of industry integration capacity. The traditional pension industry is characterised by large investments, long payback periods, and low levels of return. $\underline{28,29}$ It is not clear whether the positive effects caused by convergence can compensate for the negative effects of traditional pension services. However, the lack of internet and pension practices is still a driving force behind industry integration in the internet and pension services industry.

Third, the driving force for technical support is not strong. In areas such as business development, the internet, Big Data, and cloud computing technologies are relatively mature, but there are still problems in the pension services sector that do not match a single intelligent product type, equipment supply, and demand, and lack of communication. Only within the internal scope can be realised from complementary resources that do no interface with data exchange, which enhances Big Data's ability to fully expand cross-platform shared data and promote pension service development.

Finally, there are no systems and policies. In order to encourage the development of the aged care services industry and smart elderly care, a series of support policy documents have been issued in different provinces and cities of China. But most are scattered in the form of notices and comments in various policy documents. Their leadership role is limited and its practicality is not strong. Adverse implementations also discount some recommended policies.

According to the dynamic mechanism analysis of information and pension industry integration, the first step to promote deep integration of the information and pension industry is to strengthen the driving force of integration and reform on both sides supply and demand. Secondly, it is necessary to promote the dissemination and integration of the industry in terms of technology. In addition, the conditional role of industrial environment 
should not be ignored, and efforts should be made to create a favorable policy environment in order to provide excellent support for the integration of the internet and elderly care services.

Therefore, the policy direction for the integrated development of the internet and the pension service industry is as follows. First, the potential consumption demand of the elderly should be converted into effective consumption demand. The integration of the internet and pension services will be effectively promoted in terms of demand. In addition, in order to change the problem of insufficient consumption of the elderly, efforts should be made in terms of pension guarantee, efficiency and financial subsidies. The utilisation and acceptance rate of smart devices for the elderly will be improved.

Second, there is a need to strengthen market pioneering and improve commercial services. Only when the integration of the information and the pension industry can bring greater profits to enterprises, enterprises can spare no effort to continue to promote penetration between industries, and new forms of business will emerge and become more mature. The integration of the information and commercial services industries in the Handan region is higher than that of the pension industry. First of all, the promotion and development of the pension market should be strengthened by the commercial service industry and the retail industry, gradually forming regional pension products and pension service markets.

Third, technological innovation needs to be improved to provide technical support for integration. It is necessary to pay attention to the development of intelligent equipment that can fully understand the needs of elderly care and realise information exchange with each reservation center. And each dispatch center should be fully connected, which can form an industrial chain of information and pensions, which can greatly promote the use of shared data and greatly improve the function of big data driving.

Finally, we need to create an innovation system for integration and a good environment to support it. A sound industrial environment cannot be separated from effective institutional guarantees, and the guidelines, practicality and systems of relevant policies, including the establishment of a pension service system, the input of private capital, talent training, tax incentives, financial support and related policies, should be strengthened. In addition to the implementation of policies, laws and regulations, it is necessary to establish effective risk prevention mechanisms and responsible oversight mechanisms that can ensure the rights and interests of businesses and consumers and contributes to the sustainable development of integration on information and pension industry.

This research has few limitations despite the results of the grey relational analysis. There are a number of advantages and disadvantages in calculating the degree of industrial integration, but if the purpose of the evaluation is a better development of the traditional pension industry combined with informatisation, then the valuation methods that are commonly used should be chosen. These limitations should overcome by developing new assessment methods that address China's social aging problem. At present, China's economic policy is striving to actively develop the informationbased pension industry, and it is expected that further research will provide detailed methods. The information and pension industry, which will be studied in the future with the grey relational analysis, will be able to effectively foster and manage China's information-based pension industry.

\section{Acknowledgements}

This research was supported by Woosuk University. We would like to humbly acknowledge Woosuk University for providing us the opportunity of carrying out our research in this topic. And we also are grateful to our reviewers for their constructive suggestions.

\section{References}

1. Songzhong Y. The interaction mechanism and integration process of sports industry and pension industry. J Xian Inst Phys Educ. 2017;34(4):442-6.

2. Pengfei G. Analysis of enterprise management transformation and management model innovation driven by information technology. China Manag Inf. 2016;19(21):81-85.

3. Shaofang $Z$. The status quo, opportunities and path choice of internet care industry. Hebei J. 2016;36(4):212-6.

4. Xianyu C. Research on the measurement and improvement path of the integration level of internet and aged services in China. Contemp Econ Manag. 2019;41(7):73-80.

5. Collins DJ, Bane PW, Bradley SP. Winners or losers: industry structure in the converging world of telecommunication. Harvard Bus Rev. 1999;75(5):187-201. 
6. Weiwei L. The connotation of industrial clusters and the strategic thinking of cultivating industrial clusters in China. J Shanghai Lixin Account Inst. 2003;17(4):2-5.

7. Feng P, Feng S. "Internet +" community pension: a new thinking of intelligent pension. Learn Pract. 2015;9:99-105.

8. Hailong Z. Research on the location of wisdom home care for the elderly in chronic diseases. J Soc Sci Hunan Normal Univ. 2017;16(5):99-106.

9. Qingchao P, Dangchen Z. Analysis of the construction of the service model of "Internet + community home care for the aged” in China. Soc Sec Res. 2017;3:18-26.

10. Lien W, Zhen W, Jianing L. Research on home service innovation of integration, informatization and standardization: taking Shangcheng District of Hangzhou as an example. J Public Admin. 2013;10(3):1-10.

11. Tao H, Hong X. Social support issues and policy preferences for elderly care services for the elderly in China. Inn Mongolia Soc Sci (Chin Ver). 2015:1-12.

12. Lina G. The balance between supply and demand of home care services: an economic analysis framework based on “elasticity”. Chin J Gerontol.2019;39(5):1248-52.

13. Lixiong Y, Zhou Y. Research on the development of old-age service industry under multiple institutional logic. Nanjing Soc Sci. 2018;6:67-74.

14. Liya Z, Xiaoyang S. Research on the application and countermeasures of information technology in the aged service industry. Sci Technol Manag Res. 2015;35(5):170-74.

15. Wei Y, Yue S. "Internet + Pension": research on the innovation and development of the aged service model in the new period. J Popul Sci. 2017;39(1):58-66.

16. Yongzhi Z, Xiaobo W. "Internet + " pension service model: opportunity, dilemma and way out. J Shenzhen Univ (Hum Soc Sci Ed). 2017;34(4):109-14.

17. Yusheng L. The core issues and development direction of China's "Smart Pension" model. Shanghai Urban Manag. 2017;26(5):10-13.
18. Liqun $\mathrm{L}$. The definition of information industry and the development countermeasures of scientific and technological information institutions. Sci Manag. 1994;24(3):49-50.

19. Song H. Research on the integration and development of China's sports industry and pension industry under the background of population aging. Beijing Sport University; 2018. P. 1-6.

20. Pichat B. Population aging and its economic and social implication. New York: United Nations; 1956. P. 1-5.

21. Carroll Estes. The aging enterprise: a critical examination of social politics and services for the aged. San Francisco: Jossey-Bass; 1979. P. 1-5.

22. Lixiong Y, Zhou Y. Pension service industry: concept definition and theoretical construction. Hunan BBS. 2019;32(1):24-38.

23. Shuzhen W. Research on the innovation and development of China's pension industry based on government-enterprise cooperation. Liaoning University; 2019. P. 1-2.

24. Xiaowu C. Analysis of endowment resources. J Popul Stud. 2005;150(2):26-29.

25. Heng X, Xing R, Shao-guo Y. Wisdom for the aged: innovative aged services with information technology. Res Ageing. 2014;2(7):12-20.

26. Zhenhua Z. Industry convergence: a new motive force for industrial development and economic growth. China Ind Econ. 2003;181(4):46-52.

27. Yuqiong Z. Building a smart ageing service platform for disabled old people-from the perspective of social network. Res Ageing. 2015;3(6):48-57.

28. Jing L. A brief analysis of the status quo of population development in Handan city. Stat Manag. 2018;53(5):38-40.

29. Qiaoxing L, Kejie C. Research summary of China's pension industry based on knowledge map analysis. Technol Managt. 2019;21(6):7-17. 